УДК 621.762

\title{
ВЫБОР ТЕРМОМЕХАНИЧЕСКОГО РЕЖИМА ФОРМОВАНИЯ МИШЕНЕЙ ИЗ ПОРОШКА ТіО 2 ДЛЯ МАГНЕТРОННОГО НАНЕСЕНИЯ КОМПОЗИЦИОННЫХ ПОКРЫТИЙ ДЕТАЛЕЙ
}

\author{
А.М.ДМИТРИЕВ, Н.В.КОРОБОВА
}

Московский государственный технологический университет «Станкин», Москва, Россия

Пленочные покрытия на основе диоксида титана для деталей приборостроения с целью уменьшения их сопротивления целесообразно изготавливать из композиций с другими оксидами. Композиции желательно получать на этапе нанесения покрытия методом, в котором используют магнетроны. Сопоставлением конструкций магнетронных установок обоснована рациональность применения установки с одним магнетроном, оснащенным мишенью из композиции порошков на основе титана. Технология нанесения покрытия с использованием одного магнетрона, оснащенного композиционной мишенью, раскрыта на примере нанесения износостойких самосмазывающихся покрытий из композиции $\mathrm{Ti}+\mathrm{WS}_{2}$. Для оснащения магнетрона мишенью из порошка $\mathrm{TiO}_{2}$ ставилась задача обеспечения наибольшей равномерности распределения плотности в объеме мишени, а также достижения наибольшего значения этой плотности. В результате описанного в статье исследования технологии горячего формования порошка $\mathrm{TiO}_{2}$ показана эффективность совмещения нагрева порошка с его уплотнением в одну операцию. При выполнении этой операции экспериментально исследована зависимость плотности изготавливаемой мишени от температуры формования, давления, времени выдержки под давлением и размера зерен. Обоснован выбранный термомеханический режим формования мишени из порошка $\mathrm{TiO}_{2}$. Изготовить мишень с наибольшей плотностью позволяет следующий режим (в исследованном диапазоне) формования: температура $1300{ }^{\circ} \mathrm{C}$, давление $40 \mathrm{MПа,}$ время выдержки под давлением 20 мин, размер зерна 2,2 мкм.

Ключевые слова: диоксид титана; пленочные покрытия деталей; нанесение в магнетроне; магнетронные мишени композиционные; режимы формования мишеней; исследование

Как цитировать эту статью: Дмитриев А.М. Выбор термомеханического режима формования мишеней из порошка $\mathrm{TiO}_{2}$ для магнетронного нанесения композиционных покрытий деталей / А.М.Дмитриев, Н.В.Коробова // Записки Горного институга. 2018. Т. 232. С. 388-394. DOI: 10.31897/PMI.2018.4.388

Введение. Диоксид титана широко применяется в различных отраслях промышленности. Это характеризует его как один из важнейших стратегических материалов. Обладая свойствами полупроводника с $n$-проводимостью, диоксид титана является перспективным материалом для формирования твердых электролитов и материалов, которые обладают каталитическими свойствами.

Вместе с тем широкому использованию $\mathrm{TiO}_{2}$ в качестве твердого электролита препятствует его большое сопротивление ионной проводимости в отличие от сопротивлений других оксидов $\mathrm{Co}_{3} \mathrm{O}_{4}, \mathrm{SnO}_{2}, \mathrm{Sb}_{2} \mathrm{O}_{5}$. Анализ свойств диоксида титана и методов его синтеза $[1,3]$ указывает на возможности изменять его ионную проводимость путем введения в его состав оксидов $\mathrm{SnO}$, $\mathrm{Co}_{2} \mathrm{O}_{3}, \mathrm{Sb}_{2} \mathrm{O}_{5}, \mathrm{AgO}$, которые имеют более высокую проводимость.

Диоксид титана применяют в качестве пленочного покрытия деталей приборостроения. При этом задача повышения проводимости такого покрытия может быть решена не на этапе синтеза $\mathrm{TiO}_{2}$, а на этапе нанесения покрытия. Важные задачи современного машиностроения решаются путем сотрудничества специалистов из разных научных областей, также сотрудничества технологов и конструкторов, что связано с объединением в технологических процессах разных физико-химических технологий [13-15]. В настоящий период задачи изготовления деталей, к которым предъявляются раз-

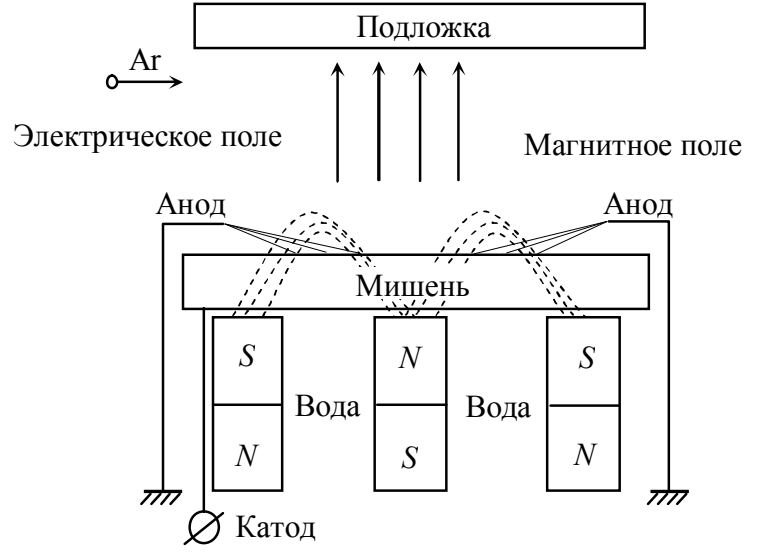

Рис.1. Схема устройства магнетрона личные требования к их глубинным и поверхностным слоям, решаются путем нанесения на детали покрытий $[2,5]$. Авторы данной статьи имеют опыт в нанесении износостойких самосмазывающихся композиционных покрытий из материалов на основе титана на детали машин и режущий инструмент $[4,6]$.

Способ нанесения покрытия. Формирование тонкопленочных покрытий осуществляется в вакуумных установках, в которых используются магнетроны. Магнетрон представляет собой систему постоянных магнитов с мощным магнитным полем, катодом и анодом, который притягивает к себе электроны (рис.1). Линии силового поля между катодом и анодом направлены перпендикулярно к силовым линиям магнитного поля. 


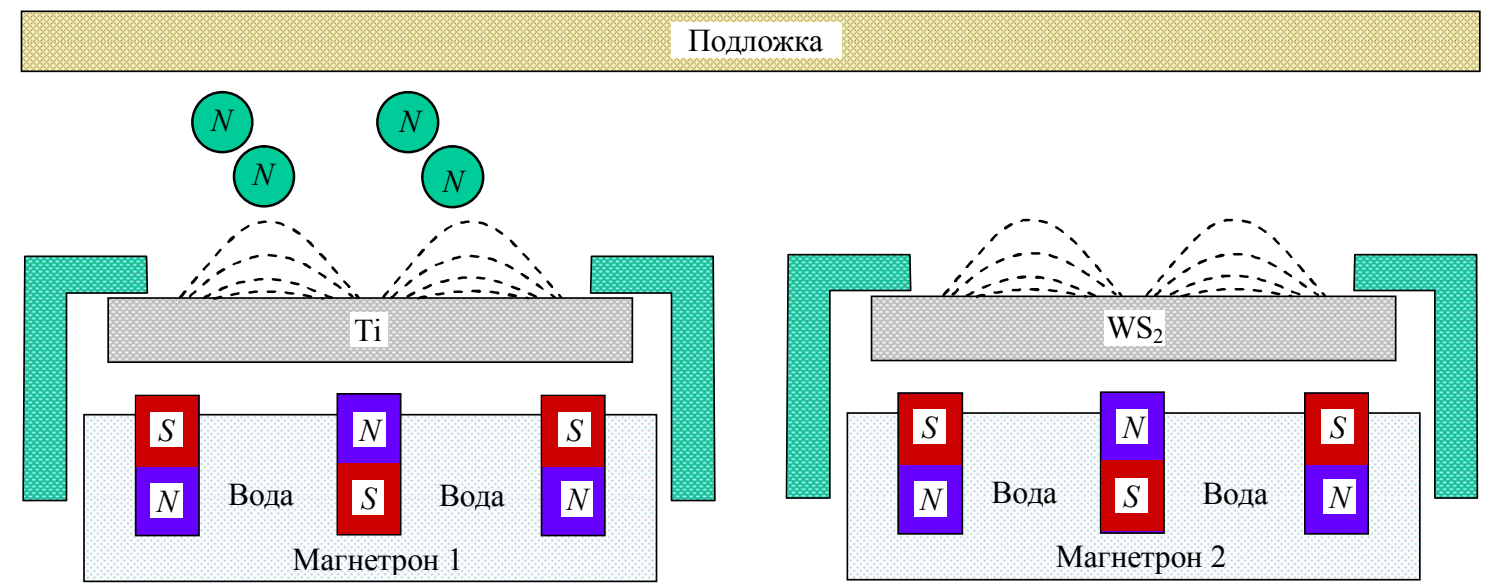

Рис. 2. Два магнетрона с мишенями из Ті и $\mathrm{WS}_{2}$

Магнетрон имеет преимущества перед другими электровакуумными приборами аналогичного назначения: электроны, благодаря увеличивающемуся пути полета, успевают совершать больше столкновений с молекулами рабочего газа, следовательно, уровень ионизации газа увеличивается. Установка может содержать как один магнетрон, так два и более (рис. 2 и 3 ).

Для получения композиционных самосмазывающихся покрытий в установках с двумя магнетронами (см. рис.2) используют две мишени из разных материалов (твердого и смазывающего). Для получения многослойного покрытия магнетроны включают попеременно, а для композиционного покрытия - одновременно. В установке с одним магнетроном (рис.3) композиционная мишень состоит из

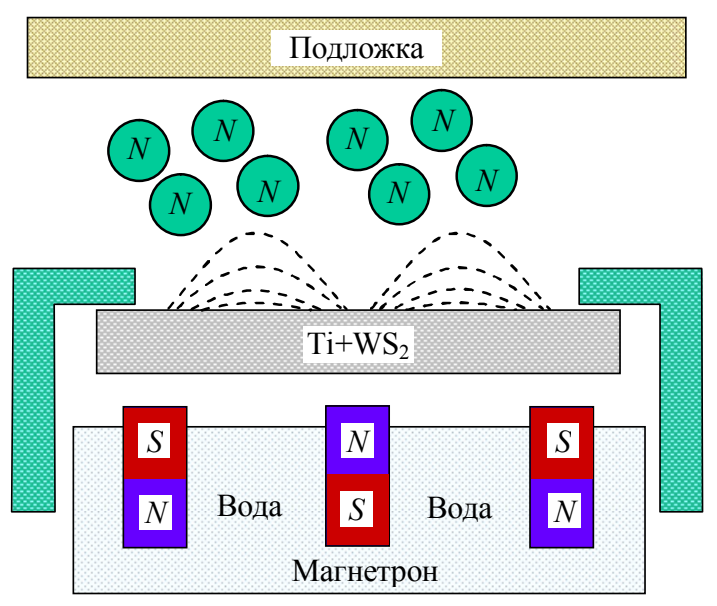

Рис. 3. Один магнетрон с композиционной мишенью смеси твердого и смазывающего компонентов.

Распыление вещества мишени происходит с помощью ионной бомбардировки. В камере магнетрона происходят следующие процессы. В перекрестных магнитном и электрическом полях траектории движения электронов в направлении от катода к аноду изгибаются. Под действием этих полей, перемещаясь в направлении своего полета, электроны вращаются. На своем пути электроны сталкиваются с атомами (или молекулами) рабочего газа и ионизируют его. Положительно заряженные ионы рабочего газа движутся к катоду и попадают в мишень. При соударении иона с мишенью ей передается энергия иона. Во внешних слоях мишени накапливается энергия, и на определенном этапе этого накопления частица вещества мишени покидает кристаллическую решетку.

После вылета из мишени частица проходит свой путь к подложке. На этом пути происходят химические и физические взаимодействия ее с веществами, находящимися в рабочей камере. Например, при нанесении нитрида титана используется мишень из чистого титана, а в качестве реактивного газа - азот; химическая реакция происходит на пути движения частицы, и на подложку осаждается уже готовое рабочее вещество. Однако, поскольку нельзя обеспечить нахождение в камере только необходимых компонентов, возможно загрязнение вещества пленки формирующегося покрытия детали примесями, например оксидами металлов.

При накоплении достаточного количества частиц рабочего вещества на поверхности подложки начинается процесс образования кристаллической решетки покрытия. Сначала частицы скапливаются у так называемых «энергетических ям» поверхности подложки и начинают организовываться локальные скопления - островки. Эти островки перемещаются в поисках устойчивого положения. Постепенно по мере накопления этих островков образуется сплошная поверхность пленки, которая впоследствии по мере роста пленки становится основой для формирования ее кристаллической структуры. 


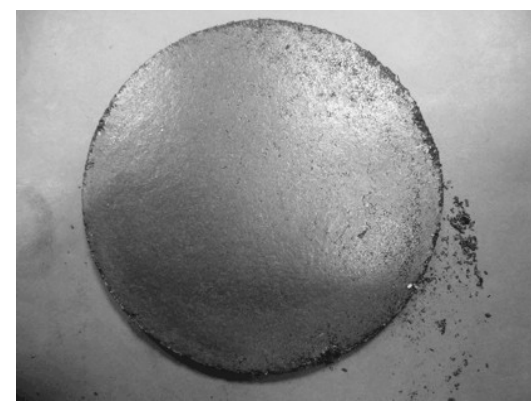

Рис. 4. Композиционная мишень из $\mathrm{Ti}+\mathrm{WS}_{2}$
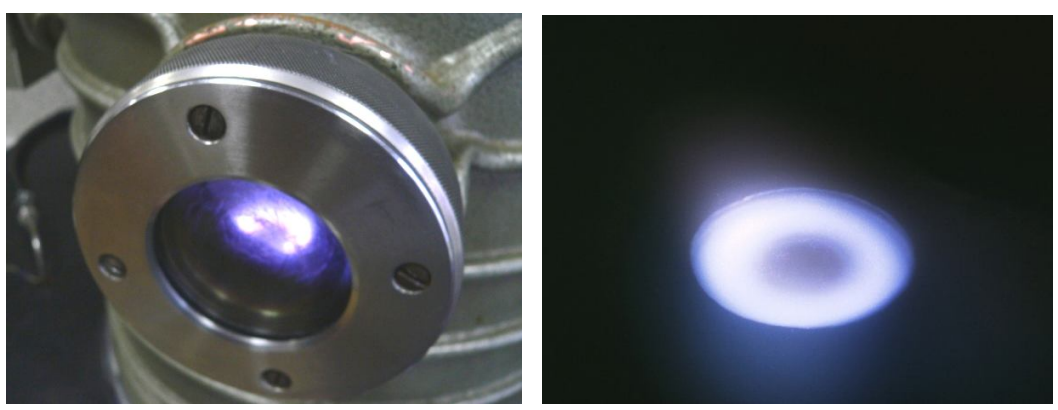

Рис.5. Мишень при работе магнетрона

Таким образом, процесс взаимодействия частицы с подложкой принципиально отличается от процессов, рассмотренных авторами работ $[8,12]$. В указанных работах исследованы взаимодействие и разрушения твердых тел при ударе одного из них по другому. Рассматриваемые в данной статье процессы взаимодействия осуществляются на размерах тел, приближающихся к наноуровням. Вследствие вылета (выбивания) частиц из мишени и попадания их на подложку частицы совершают созидательный процесс, и образуется прочное покрытие детали или, возможно, технологического инструмента. Сравнение рассматриваемого процесса с процессами, описанными в работах $[8,12]$, показало, что деталь, имеющая нанесенное магнетронным способом покрытие, способна оказать большее сопротивление динамическому воздействию при ударе по ней другого тела.

Мишень магнетрона до начала ее применения, сформованная из порошкового материала, показана на рис.4. Мишень при работе магнетрона выглядит как показано на рис.5.

Формирование и эффективность износостойкого самосмазывающегося покрытия. Покрытие формировалось в следующей последовательности и при следующих режимах: дегазация мишени 3 ч; подготовка поверхности образцов в ультразвуковой ванне, обезжиривание и ионнолучевое травление 30 мин; нанесение покрытия при давлении аргона 0,1 Па, напряжение разряда на магнетроне $800 \mathrm{~B}$, ток разряда 0,6-1,6 А, расстояние до образцов 180 мм, скорость осаждения частиц до 5 нм/мин.

Данные по значению коэффициента «сухого трения» изготовленных деталей показывают, что покрытие, полученное из композиции $\mathrm{Ti}+\mathrm{WS}_{2}$ (порошок чистого титана и дисульфид вольфрама), обеспечивает снижение коэффициента трения в 2 раза по сравнению с образцом без покрытия. В случае композиции $\mathrm{TiN}+\mathrm{WS}_{2}$ (порошок из перемолотой стружки $[4,6]$ и дисульфида вольфрама) это снижение составляет 2,3 раза. Эффективна ее гидроструйная обработка как способ предварительной подготовки поверхности детали перед нанесением покрытия [7].

Решаемая с помощью самосмазывающегося покрытия задача в обработке давлением альтернативна задаче по использованию активно направленных сил контактного трения между заготовкой и инструментом для повышения эффективности производственного процесса [10]. Также отметим, что помимо технологии с использованием магнетронов специалисты по обработке давлением располагают другими технологиями [9] управления микроструктурой и, как следствие, механическими свойствами деформированных металлов.

Методика исследования процесса формования мишени для магнетрона на основе двуокиси титана. Изготовление мишеней показанного на рис.4 типа из порошков на основе двуокиси титана можно осуществлять по двум технологиям: 1) холодное формование порошка в закрытой матрице - спекание - горячая штамповка пористой заготовки в закрытой матрице; 2) горячее формование мишени непосредственно из порошка в закрытой матрице. Недостатком первой из названных выше технологий является трудность обеспечения равномерного распределения плотности в объеме мишени. При отсутствии равномерного распределения плотности происходит неравномерная усадка мишени при спекании. В результате наблюдается коробление мишеней и образование в них трещин. Помимо этого, требуется дополнительное технологическое оборудование для спекания и последующей горячей штамповки сформованной и спеченной пористой заготовки. Ввиду этих недостатков предпочтение отдано второй технологии. При этом необходимо обеспечивать нагрев порошка до заданной температуры непосредственно в матрице. 
Схема установки для реализации второй технологии приведена на рис.6.

Между плитами пресса размещена печь с силитовыми нагревателями. Конструкция печи допускает ее быструю разборку для установки и извлечения матрицы с заготовкой. Печь имеет отверстия, в которые входят формующие порошок пуансоны, а также отверстие для установки термопары. Температура в печи регулируется путем изменения напряжения на силитовых нагревателях. Поскольку нагрев керамических порошков производится непосредственно в матрице, установленной внутри нагревательной установки, их уплотнение можно считать изотермическим. Температурный интервал горячего формования пластин $1200-1300{ }^{\circ} \mathrm{C}$.

Необходимость поддержания высокой температуры обусловливает специфические требования по жаропрочности к материалам, из которых изготавливается инструментальная оснастка. Для изготовления рабочих деталей оснастки применяется карбид кремния, обладающий высокой

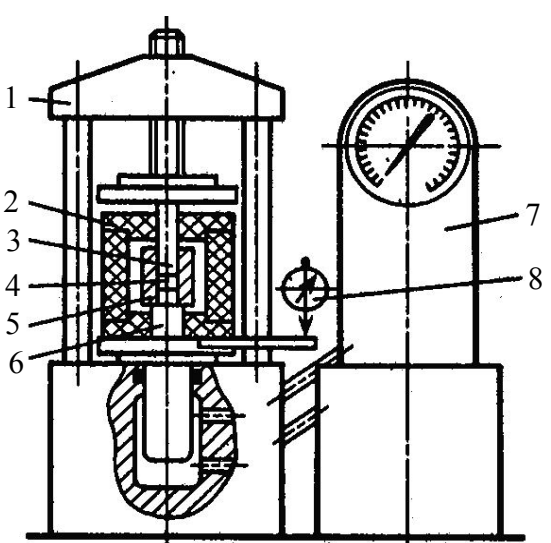

Рис.6. Схема установки для нагрева порошка и формования пластины 1- испытательная машина Инстрон-350; 2 - печь; 3 - верхний пуансон; 4 - изделие; 5 - матрица; 6 - нижний пуансон; 7 - гидропривод машины;

8 - индикатор перемещений инструмента прочностью на сжатие, износостойкостью, жаростойкостью, сохраняющий высокие механические характеристики при повышенных температурах. Карбид кремния имеет высокую термостойкость и теплопроводность, температура его плавления $2600{ }^{\circ} \mathrm{C}$. Рабочие детали штампа из карбида кремния выдерживают 40 и более циклов нагружений при температуре $1300{ }^{\circ} \mathrm{C}$. Предотвращение приваривания порошковой заготовки к инструменту обеспечено разделительным слоем из диоксида циркония. Толщина разделительного слоя примерно 1 мм.

Горячее формование мишени из порошка $\mathrm{TiO}_{2}$ включает в себя две стадии. На первой стадии происходит кратковременное деформирование, а на второй - пластическая деформация во времени. Вторую стадию Н.Н.Малинин назвал кратковременной ползучестью. Продолжительность второй стадии при формовании мишеней измеряется десятками минут.

В проведенном исследовании с помощью следящей системы испытательной машины Инстрон-350 обеспечено горячее изостатическое формование порошка $\mathrm{TiO}_{2}$. Оно было направлено на определение зависимости плотности изделия от температуры, при которой производится формование, давления сжатия порошка, времени выдержки под давлением, дисперсности порошка.

Дисперсность порошка (размер зерна) была рассмотрена в качестве варьируемого параметра, поскольку в работе [11] по горячей штамповке титана указывается на существенное влияние этого размера. Формование производилось при температуре, соответствующей наибольшей пластичности материала. Верхняя граница интервала наибольшей пластичности для исследуемого материала равна $1300{ }^{\circ} \mathrm{C}$. В проведенном исследовании нижнюю границу температурного интервала горячего формования приняли равной $1100{ }^{\circ} \mathrm{C}$. Штамповая оснастка из карбида кремния выдерживает удельные силы (усредненные давления) до 40 МПа. Диапазон изменения давления 20-40 МПа. Верхняя граница диапазона выдержек под давлением 50 мин. Нижняя граница исследованного диапазона 10 мин. В исследовании применены порошки с размером зерен 2,2; 2,7; 3,5; 4,3; 4,54 мкм.

Размеры частиц порошка были обеспечены путем его просева с использованием электромеханического сита периодического действия, приводимого в винтовые возвратные колебания виброприводом. Сито обладало герметизацией, возможностью применения тонких сеток для просева порошков мелких фракций. Частота колебаний сита составляла 20-50 Гц, амплитуда колебаний 2 мм. В процессе просева частоту колебаний ступенчато меняли. В течение первых 10 мин она составляла 20 Гц, следующих 10 мин - 25 Гц, заключительные 10 мин - 50 Гц. При подготовке порошков для описанного эксперимента просев начинался через наиболее мелкую сетку - 2,2 мкм. Фракция порошка с заданным размером после прохождения через сетку высыпалась в поддон, а порошок более крупных фракций перемещался по кольцу. После окончания просева не прошедший через сетку порошок более крупных фракций удалялся из сита и в сите заменяли сетку на более круп- 


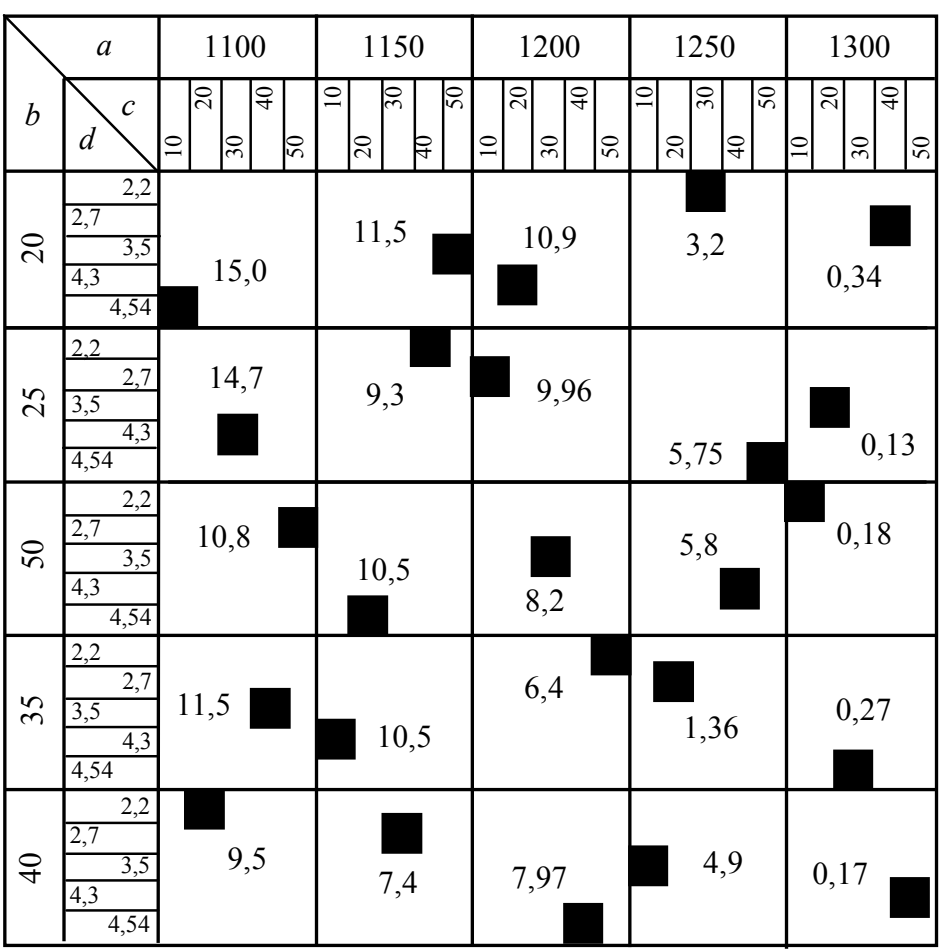

Рис.7. Комбинационный квадрат, показывающий значения четырех рассматриваемых параметров в каждом из 25 проведенных опытов ную. В данном исследовании на втором этапе - 2,7 мкм. В сито загружали порошок, изъятый после первого просева, и просев возобновлялся через вторую сетку. Таким образом, были подготовлены порошки пяти примененных в эксперименте фракций. Заметим, что наряду с приведенными значениями фракций частиц, во всех опытах имели место незначительные включения более мелких фракций. Эти незначительные включения не оказали какого-то заметного влияния на результат исследования, описанный при обсуждении результатов статьи.

Исследование направлено на отыскание параметров процесса, при которых достигается наиболее высокая плотность мишени. Плотность оценивали по значению весового водопоглощения в процентах. Для этого предварительно взвешенное с точностью до 0,0001 г изделие подвергали кипя-

чению в течение 15 мин и последующему охлаждению в воде. После охлаждения изделие вновь взвешивали, подсчитывали разность весов до и после кипячения, и эту разность относили к весу сухого образца.

Авторы статьи использовали методику планирования эксперимента и обработки его результатов, предложенную М.М.Протодьяконовым и Р.И.Тедером (рис.7).

В больших клетках приведенного на рис.7 комбинационного квадрата отмечены измеренные по описанной выше методике величины водопоглощения (в процентах) образцов, сформованных при сочетании параметров, соответствующих малым клеткам, где $a$ - температура, ${ }^{\circ} \mathrm{C} ; b-\mathrm{yдель-}$ ная сила (усредненное по поверхности образца давление), МПа; $c$ - время выдержки под давлением, мин; $d$ - размер зерна, мкм.
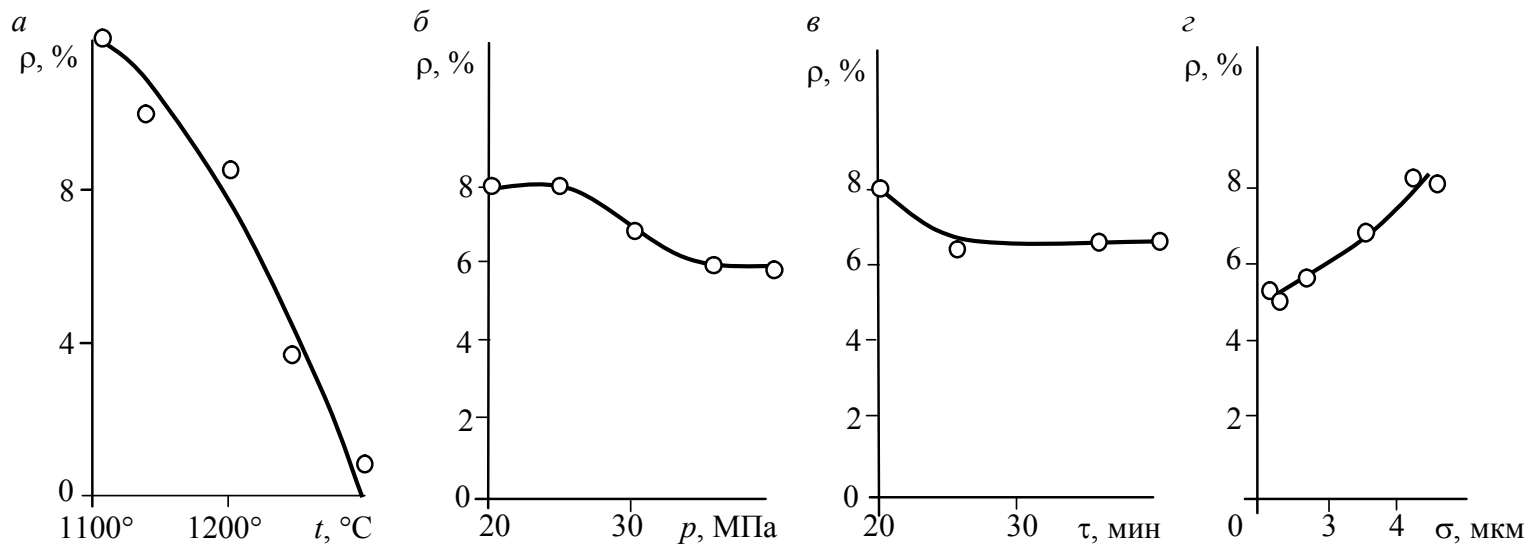

Рис. 8. Зависимости водопоглощения $\rho$ образцов мишеней от температуры формования $(a)$, давления (б), времени выдержки под давлением (в) и размера зерен (2) 
Выбор термомеханического режима формования мишеней ...

Результаты исследования горячего формования мишеней из порошка $\mathrm{TiO}_{2}$. Результаты опытов, способ обработки результатов данных и зависимость водопоглощения ( $\rho$ ) изделия от каждого из четырех параметров процесса при усредненном влиянии трех приведены в табл. 1 и 2. По результатам обработки экспериментальных данных построены представленные на рис. 8 зависимости.

Таблица 1

Результаты в зависимости от температуры и давления

\begin{tabular}{c|c|c|c|c|c|c|c}
\hline \multirow{2}{*}{ Давление, МПа } & \multicolumn{7}{|c}{ Водопоглощение, \% } \\
\cline { 2 - 8 } & $t=1100{ }^{\circ} \mathrm{C}$ & $t=1150{ }^{\circ} \mathrm{C}$ & $t=1200{ }^{\circ} \mathrm{C}$ & $t=1250{ }^{\circ} \mathrm{C}$ & $t=1300{ }^{\circ} \mathrm{C}$ & $\begin{array}{c}\text { Сумма } \\
\text { по строке }\end{array}$ & $\begin{array}{c}\text { Среднее } \\
\text { по строке }\end{array}$ \\
\hline 20 & 15,0 & 11,5 & 10,9 & 3,2 & 0,34 & 40,94 & 8,188 \\
25 & 14,7 & 9,3 & 9,96 & 5,75 & 0,13 & 39,84 & 7,968 \\
30 & 10,8 & 10,5 & 8,2 & 5,6 & 0,18 & 35,28 & 7,056 \\
35 & 11,5 & 10,5 & 6,4 & 1,36 & 0,2 & 29,96 & 5,992 \\
40 & 9,5 & 7,4 & 7,97 & 4,9 & 0,17 & 29,94 & 5,988 \\
Сумма по столбцу & 61,5 & 49,2 & 43,43 & 20,81 & 1,02 & 175,96 & - \\
Среднее по столбцу & 12,3 & 9,84 & 8,686 & 4,162 & 0,5044 & - & 35,392
\end{tabular}

Таблиия 2

Результаты в зависимости от времени выдержки под давлением и размера зерна

\begin{tabular}{c|c|c|c|c|c|c|c}
\hline \multirow{2}{*}{ Размер зерна, мкм } & \multicolumn{7}{|c}{ Водопоглощение, \% } \\
\cline { 2 - 8 } & $\tau=20$ мин & $\tau=20$ мин & $\tau=30$ мин & $\tau=40$ мин & $\tau=50$ мин & $\begin{array}{c}\text { Сумма } \\
\text { по строке }\end{array}$ & $\begin{array}{c}\text { Среднее } \\
\text { по строке }\end{array}$ \\
\hline 2,2 & 0,18 & 9,5 & 3,2 & 9,3 & 6,4 & 28,58 & 5,716 \\
2,7 & 9,96 & 1,36 & 7,4 & 0,34 & 10,8 & 29,86 & 5,972 \\
3,5 & 4,9 & 0,13 & 8,2 & 11,5 & 11,5 & 36,23 & 7,246 \\
4,3 & 10,5 & 10,9 & 14,7 & 5,6 & 0,17 & 41,87 & 8,374 \\
4,54 & 15,0 & 10,5 & 0,2 & 7,97 & 5,75 & 39,42 & 7,884 \\
Сумма по столбцу & 40,54 & 32,39 & 33,7 & 34,71 & 34,62 & 175,96 & - \\
Среднее по столбцу & 8,108 & 6,478 & 6,74 & 6,942 & 6,924 & - & 35,392
\end{tabular}

Обсуждение результатов. Наибольшее влияние на водопоглощение мишени, т.е. на ее плотность, оказывает температура горячего формования (рис.8). При приближении к $1300{ }^{\circ} \mathrm{C}$ повышение температуры на несколько градусов существенно увеличивает плотность изделия. В то же время изменение давления сжатия порошка от 35 до 40 МПа практически не влияет на плотность изделия. Следовательно, в процессе горячего формования давление можно поддерживать менее тщательно, чем температуру. Увеличение времени выдержки под давлением при формовании более 20 мин практически не влияет на плотность изделий. Средний размер зерна формуемого порошка оказывает значительное влияние на плотность изделия. На полученной зависимости это влияние убывает при размере зерна менее 2,5 мкм.

Заключение. При сочетании четырех исследованных параметров (температура $1300{ }^{\circ} \mathrm{C}$, давление 40 МПа, время 20 мин и размер зерна 2,2 мкм), позволяющем изготовить мишень с наибольшей плотностью, оценена зависимость плотности от формы и размеров изделия в плане. Дополнительный эксперимент показал, что форма и размеры в плане практически не влияют на плотность изделия.

\section{ЛИТЕРАТУРА}

1. Дамаскин Б.Б. Электрохимия / Б.Б.Дамаскин, О.А.Петрий, Г.А.Цирлина. М.: Химия, 2006. 670 с.

2. Износостойкость композиционных покрытий для режущего инструмента / М.Ш.Мигранов, А.М.Мигранов, С.М.Мингалеев, С.Р.Шехтман // Вестник МГТУ «Станкин». 2017. № 4(43). С. 38-42.

3. Моррисон С. Химическая физика поверхности твердого тела. М.: Мир, 1980. 488 с.

4. Создание на основе переработки титановой стружки наноструктурированных износостойких самосмазывающихся покрытий на поверхностях деталей машин и технологического инструмента / А.М.Дмитриев, А.И.Беликов, Н.В.Коробова, Ю.В.Панфилов // Технология легких сплавов. 2010. № 3. С.79-86.

5. Сотова E.C. Технология нанесения AG-содержащего покрытия на полимерные изделия медицинского назначения для усиления их антибактериального действия / Е.С.Сотова, С.В.Федоров // Вестник МГТУ «Станкин». 2017. № 4 (43). С. 33-37. 
Выбор термомеханического режима формования мишеней ...

6. Технология создания наноструктурированных износостойких покрытий с использованием отходов титана / А.М.Дмитриев, А.И.Беликов, Н.В.Коробова, Ю.В.Панфилов // Ремонт, восстановление, модернизация. 2010. № 4. С. $30-33$.

7. Федоров С.В. Гидроструйная обработка как способ предварительной подготовки поверхности твердого сплава перед нанесением износостойкого покрытия / С.В.Федоров, Д.Вайс, Х.Со.Мин // Вестник МГТУ «Станкин». 2017. № 4 (43). С. $48-51$.

8. Collins J.A. Failure of materials in mechanical design. New York: John Wiley \& Sons, 1981. P.188-193.

9. Correlanion between microstructure and mechanical properties of severely deformed metals / J.Gubicza, N.Q.Chinh, J.L.La'ba'r, Z.Hegedus, S.Dobatkin, T.G.Langdon // Journal of Alloys and Compounds. 2009. Vol. 483. № 1-2. P.271-274.

10. Dmitriev A.M. Expanding of Application of Cold Die Forging by Inducing Active Contact Friction Forces / A.M.Dmitriev, N.V.Korobova // Journal of Friction and Wear. 2013. Vol. 34. P.232-237.

11. Huang T.-H. Effect of grain size on mechanical revolution of pure titanium and die cavity filling rate in hot squeezing mini spur-gear forming process / T.H.Huang, C.P.Jiang, F.V.Grechnikov // International Journal of Precision Engineering and Manufacturing. 2017. Vol.18. Iss. 10. P.1371-1377.

12. Johnson $W$. Rupert's glass drops: Residual-stress measurements and calculations and hypotheses for explaining disintegration fracture / W.Johnson, S.Chandrastrar // Journal of Materials Processing Technology. 1992. Vol. 31. P. 413-440.

13. Macsarov V.V. Managing the Process of Chip Formation by Preliminary Local Action on the Worcable Surface of the Worcpiece / V.V.Macsarov, J.Olt // Journal of Mechanical Engineering. 2008. № 6. 45 p.

14. Madissoo M. Testing of the External Tool Holder Equipped with Alternate in its Construction / M.Madissoo, A.Rassner, V.Maksarov, J.Olt // Material Science. 2015. Vol. 21. № 3. P.391-395.

15. Olt J. Dynamic Simylation of Chip Formation in the Process of Cutting / J.Olt, F.Liyvapuu, M.Madissoo, V.Maksarov // International Journal of Materials \& Product Technology. 2016. Vol. 53. № 1. P. 1-14.

Aвторы: А.М.Дмитриев, д-р техн. наук, профессор, ил.-кор. PAH, countess.olga@gmail.com (Московский государственный технологический университет «Станкин», Москва, Россия), Н.В.Коробова, д-р техн. наук, заведующая кафедрой, эксперт PAH, mt-6@yandex.rи (Московский государственный технологический университет «Станкин», Москва, Россия).

Статья поступила в редакиию 03.02.2018.

Статья принята к публикаџчи 10.05.2018. 